\title{
SARS-CoV-2: a new dimension to our understanding of coronaviruses
}

\author{
Yusha Araf $^{1} \cdot$ Nairita Ahsan Faruqui ${ }^{2} \cdot$ Saeed Anwar $^{3} \cdot$ Mohammad Jakir Hosen $^{1}$ (]
}

Received: 10 August 2020 / Revised: 13 November 2020 / Accepted: 16 November 2020 / Published online: 24 November 2020

(C) Springer Nature Switzerland AG 2020

\begin{abstract}
Coronaviruses have marked their significant emergence since the twenty-first century with the outbreaks of three out of the seven existing human coronaviruses, including the severe acute respiratory syndrome coronavirus (SARS-CoV) in 2003, Middle East respiratory syndrome coronavirus (MERS-CoV) in 2012, and severe acute respiratory syndrome coronavirus 2 (SARS-CoV-2) in 2019. These viruses have not only acquired large-scale transmission during their specified outbreak period, but cases of MERS$\mathrm{CoV}$ still remain active, although there is only limited transmission. While, on the other hand, SARS-CoV-2 continues to remain a rising threat to global public health. The recent novel coronavirus, SARS-CoV-2, responsible for the ongoing coronavirus disease 2019 (COVID-19), emerged during December 2019 in Wuhan, China, and has repeatedly raised questions about its characteristic variability. Despite belonging to the same family, SARS-CoV-2 has proven to be quite difficult to control and contain in terms of transmissibility, leading to around 19.8 million reported cases and more than 730,000 deaths of individuals worldwide. Here, we discuss how SARS-CoV-2 differs from its two other related human coronaviruses in terms of genome composition, site of infection, and transmissibility, among several other notable aspects - all indicating to the possibility that it is these variations in addition to other unknowns that are contributing to this virus' differing deadly pattern.
\end{abstract}

Keywords Coronavirus $\cdot$ SARS-CoV $\cdot$ MERS $\cdot$ SARS-CoV-2 $\cdot$ Transmissibility $\cdot$ Genome $\cdot$ ACE2 $\cdot$ Case fatality rate

\section{Introduction}

The emergence of deadly viral infections has significantly affected human health despite the extraordinary efforts in management, therapeutics, and vaccine developments over the years. Viruses are sub-microscopic infectious agents that consist of an RNA or DNA genome enclosed within a protein coat called capsid; in some cases, they might have an outer envelope of lipids. These agents invade living cells and use their host's molecular machinery to replicate their own genetic material. While these agents can be of various types, a newly

Mohammad Jakir Hosen

jakir-gen@sust.edu

1 Department of Genetic Engineering and Biotechnology, School of Life Sciences, Shahjalal University of Science and Technology, Sylhet, Bangladesh

2 Biotechnology Program, Department of Mathematics and Natural Sciences, School of Data and Sciences, BRAC University, Dhaka, Bangladesh

3 Department of Medical Genetics, Faculty of Medicine \& Dentistry, University of Alberta, Edmonton, AB, Canada identified strain from the Coronaviridae family had emerged in China in December 2019, known as severe acute respiratory syndrome coronavirus 2 (SARS-CoV-2). This virus is responsible for the current worldwide pandemic of respiratory illness, called the coronavirus disease 2019 (COVID-19).

Coronaviruses are known to infect animals and humans, causing respiratory, gastrointestinal, hepatic, and neurologic disorders. Coronaviruses belong to the subfamily Orthocoronavirinae, which is mainly classified into four genera: Alpha-coronavirus, Beta-coronavirus, Gammacoronavirus, and Delta-coronavirus (Payne 2017; King et al. 2011). Among the known coronaviruses, seven coronaviruses have been identified to be associated with humans. Within these seven human coronaviruses, three beta-coronaviruses already well known for the outbreaks are SARS-CoV (which had an outbreak in 2002, in Guangdong, China), MERS-CoV (which emerged in Saudi Arabia in 2012, and still involves both the circulation in camels and a limited human-to-human transmission in several countries), and SARS-CoV-2 (Drosten et al. 2003; Zaki et al. 2012; Zhu et al. 2020). Although the known human coronaviruses mainly cause respiratory infections, the beta variants primarily attack the upper respiratory tract. MERS-CoV and SARS-CoV 
usually have easier access and therefore successfully infect the lungs (Cyranoski 2020). Surprisingly, SARS-CoV-2 can efficiently infect both the upper respiratory tract and lungs. Similarly, unlike SARS-CoV, SARS-CoV-2 was also observed to have replicated in neuronal cells of COVID-19 patients, representing their potential to cause significant neural symptoms such as anosmia, confusion, and ageusia, which are rarely reported in patients with SARS-CoV (Chu et al. 2020).

This review highlights the differential traits of SARS-CoV2, from SARS-CoV and MERS-CoV, in order to provide possible evidence of its characteristic variation in traits. These traits depict its potential pattern of transmissibility, structural differences, and therapeutic approaches.

\section{Genome and structural composition}

SARS-CoV-2 is an enveloped, non-segmented, positive-sense RNA virus with a diameter of about $65-125 \mathrm{~nm}$. It consists of crown-like spikes on its outer surface. The strains SARS$\mathrm{CoV}-2$ and a bat SARS-related coronavirus (SARSr-CoV; RaTG13) were initially thought to be closely associated (Zhou et al. 2020). Moreover, even though molecular analysis of these strains revealed only a $4 \%$ variability in genomic nucleotides, a difference of $\sim 17 \%$ at neutral sites indicated a much more significant divergence than previously assumed (Tang et al. 2020). A phylogenetic tree analysis revealed that SARS-CoV-2, along with SARS-CoV and bat SARS-like coronavirus, belongs to a different clade than MERS-CoV. It was also seen to be more phylogenetically related to bat SARS-like coronaviruses than to the usual SARS-CoV. This suggests a different viral evolution from SARS-CoV and MERS-CoV, involving bats as a wild reservoir $(\mathrm{Wu}$ et al. 2020; Benvenuto et al. 2020; Chan et al. 2020a, b; Lu et al. 2020; Paraskevis et al. 2020; Petrosillo et al. 2020).

SARS-CoV-2 constitutes four major structural proteins, which include spike (S) glycoprotein, small envelope (E) glycoprotein, membrane (M) glycoprotein, and nucleocapsid (N) protein, and several accessory proteins (Jiang et al. 2020) (Fig. 1). The spike or $\mathrm{S}$ glycoprotein is a transmembrane protein found in the outer surface of the virus. It forms homotrimers protruding from the viral surface and facilitates the virus particle to bind to host cells with the help of angiotensinconverting enzyme 2 (ACE2) receptors that are expressed in lower respiratory tract cells as well as utilizing the serine protease TMPRSS2, for S protein priming (Hoffmann et al. 2020). The host cell's furin-like protease cleaves this S glycoprotein into two subunits, an N-terminal S1 subunit and a membrane-bound C-terminal S2 region (Astuti 2020; Coutard et al. 2020). The S1 subunit consists of a receptorbinding domain (RBD) that recognizes explicitly ACE2 as its receptor, and the S2 subunit facilitates the virus fusion in transmitting host cells (Guo et al. 2020b; Fehr and Perlman
2015; Walls et al. 2020). The N protein or nucleocapsid is localized in the endoplasmic reticulum-Golgi region bound to the virus's nucleic acid material; this enables the $\mathrm{N}$ protein to be involved in processes that include the viral genome, its replication cycle, and also the response of the host cells to the viral infection (Tai et al. 2020). The membrane or M protein determines the shape of the virus envelope along with its ability to bind to all the other structural proteins, and the envelope or E protein, which is known to be the smallest protein of the SARS-CoV structure, contributes to the production and maturation of the virus (Schoeman and Fielding 2019). Moreover, the entry of the viruses into their host cells is facilitated by different receptors. Dipeptidyl-peptidase 4 (DPP4) is the receptor for only MERS-CoV, and ACE2 is the receptor for both SARS-CoV and SARS-CoV-2, to enter cells and infect the human body or other organisms (Zhou et al. 2020; Mou et al. 2013).

\section{Transmission pattern}

Several studies have contributed to the possibility of higher transmissibility of SARS-CoV-2 compared to SARS-CoV or MERS-CoV. The affinity of SARS-CoV-2 to ACE2 was 10 20 times higher than SARS-CoV, suggesting the possibility of a higher transmitting ability (Wrapp et al. 2020). Current studies also revealed the $\mathrm{S}$ protein as the initial target of neutralizing antibodies, and a closer look into their structure can be of possible significance ( $\mathrm{Yu}$ et al. 2020). Moreover, another study showed that three mutations in S protein's receptorbinding domain could bring about changes in its antigenicity (Phan 2020). Another source of mutation could be the 12 inserted bases in a gene at the junction between the coding regions of S1 and S2; this introduces furin proteolytic sites in the glycoprotein, increasing the transmissibility of SARSCoV-2 (Li et al. 2020). The basic reproduction number $\left(R_{0}\right)$ is the average number of secondary cases generated by a primary case in a population of susceptible individuals. While different studies estimated different $R_{0}$ values depending on the variation in methods, regions, and sample sizes, they all further indicate an enhanced transmission ability of SARSCoV-2 (Table 1) (Guo et al. 2020a).

Apart from the assumed higher transmissibility, SARSCoV-2 attains its lethal characteristics compared to the other coronaviruses through an array of adaptation processes. Unlike the others, they are also known to readily attack human cells at varying points, primarily targeting the lungs and the throat. The accumulation of mutations may lead to a decrease in the severity of infection caused by the virus. However, several commonly used antivirals, mostly nucleoside analogs, e.g., ribavirin, incorporate into viral genomes and disrupt viral replication, which is often ineffective towards coronavirus' genomic proofreading mechanisms. These mechanisms may, 
Fig. 1 Genome organization of a SARS-CoV-2, b SARS-CoV, and c MERS-CoV. All three viruses consist of the $5^{\prime}$-untranslated region (5'-UTR), polyprotein with open reading frame $(\mathrm{ORF}) 1 \mathrm{a} / \mathrm{b}$, which represent non-structural proteins for replication, structural S glycoproteins, $M$ proteins, E proteins, and $\mathrm{N}$ proteins. They further comprise accessory proteins - ORF $3 \mathrm{a} / \mathrm{b}, 5,6,7 \mathrm{a} / \mathrm{b}$, $8 \mathrm{a} / \mathrm{b}, 9 \mathrm{~b}$ and 10 , and the $3^{\prime}$-untranslated region ( $\left.3^{\prime}-\mathrm{UTR}\right)$. The diagram also represents dotted lines, below and above the structures, which are the marker proteins to demonstrate the key differences among SARS-CoV-2, SARS-CoV, and MERS-CoV.

The diagram is not drawn to scale

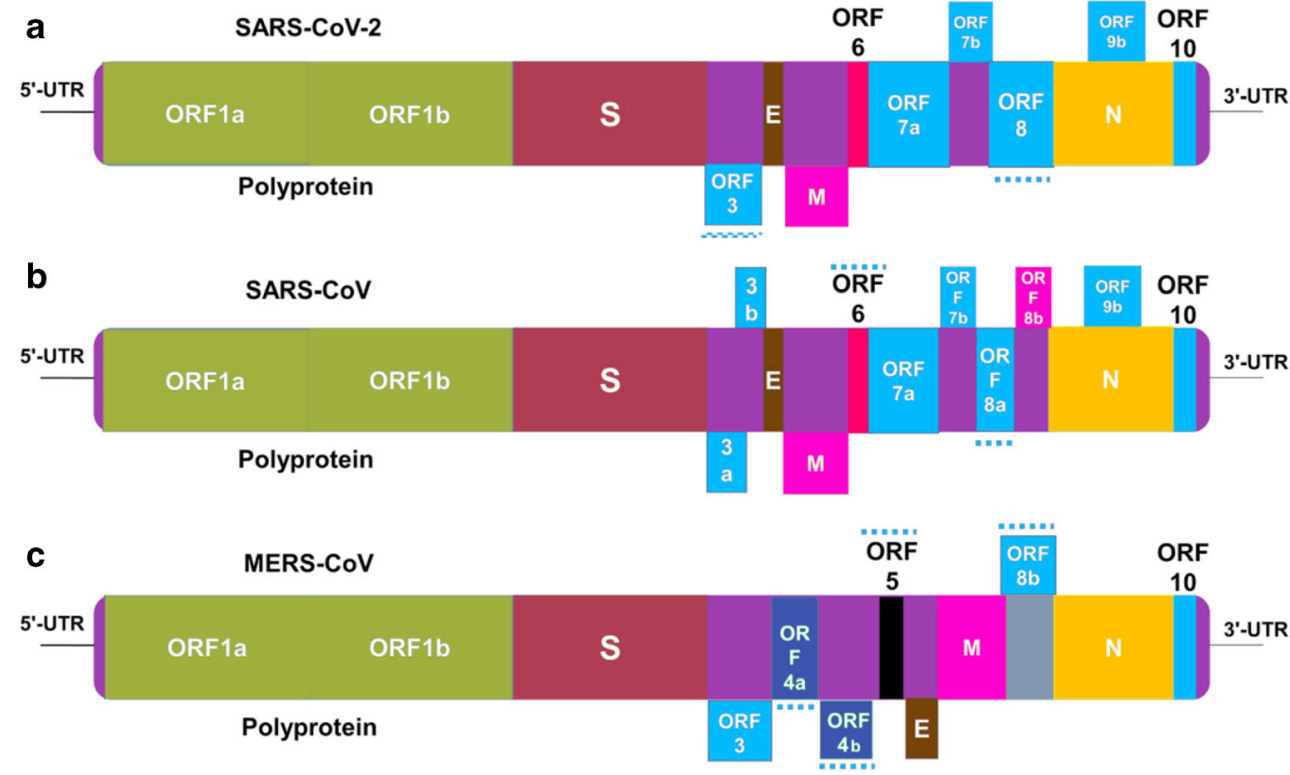

in turn, prevent the accumulation of any mutation in the virus genome, reassuring its stability and proving the possible ineffectiveness of such antivirals that work by inducing mutations (Robson et al. 2020). Studies involving viral cultures from several COVID-19 patients showed mild symptoms which revealed that the virus was actively replicating in the upper respiratory tract; it was also reproducing and infectious (Wölfel et al. 2020). The observations from these studies concluded that, in SARS-CoV-2, the viral particles spread from the throat to the saliva before showing any apparent symptoms, which can then easily pass from one person to another. This was not the case with SARS-CoV, therefore making it easier to contain and control previously. All three of these human coronaviruses among the existing seven show a clinical spectrum from asymptomatic or mild to severe symptoms and may even lead to deaths. They are also seen to have more typical effects on older people, weakened immune systems, and those with chronic diseases. While they have moderately similar symptoms, the viruses that are the causative agents of
SARS-CoV and MERS-CoV do not usually spread before the development of the disease, but SARS-CoV-2 appears to be transmissible days before the visibility of symptoms (European Centre for Disease Prevention and Control 2020; World Health Organization 2020).

\section{Differential traits}

Despite many similarities between SARS-CoV and SARSCoV-2, they have different traits regarding their attachments to the ACE2 receptor. Even though both SARS-CoV and SARS-CoV-2 bind with ACE2 receptors, the spread of SARS-CoV-2 is further aided, due to its complementary fit to the receptor-binding domain. Therefore, SARS-CoV-2 is 10-20 times more likely to bind to ACE2 than SARS-CoV (Cyranoski 2020; Wrapp et al. 2020). Moreover, SARS-CoV2 is also known to utilize the enzyme furin, abundant in the human respiratory tract, to cleave the viral spike proteins. The

Table 1 Clinical outcomes and epidemiological data of SARS, MERS, and COVID-19 (Tang et al. 2020; Paraskevis et al. 2020; Jiang et al. 2020; Gisanddata.maps.arcgis.com 2020). This table represents data until 31 July 2020

\begin{tabular}{llll}
\hline Features & SARS-CoV & MERS-CoV & SARS-CoV-2 \\
\hline Major symptoms & $\begin{array}{c}\text { Fever, malaise, myalgia, headache, } \\
\text { diarrhea, shivering, shortness of } \\
\text { breath, and coughing }\end{array}$ & Fever, coughing, shortness of breath & $\begin{array}{c}\text { Fever, coughing, shortness } \\
\text { of breath, pneumonia }\end{array}$ \\
Phylogenetic origin & Clade I, cluster IIb & Clade II & Clade I, cluster IIa \\
Incubation period & $2-7$ days & $5-6$ days & $7-14$ days \\
$R_{0}$ values & $1.7-1.9$ & $<1$ (less than 1) & $2.0-2.5$ (estimated) \\
Total cases/deaths & $8096 / 774$ & $2519 / 866$ & $17,321,394 / 673,822$ \\
Fatality rate & $9.6 \%$ & $34.4 \%$ & $2.3 \%$ \\
Countries affected & 29 & 27 & 188 \\
\hline
\end{tabular}


cleavage molecules that facilitate the spread of SARS-CoV are much less available and ineffective than those of SARSCoV-2 (Cyranoski 2020; Shang et al. 2020). The inclusion of furin may provide evidence of the aided transmission from cell to cell, person to person, and possibly animal to human in cases of SARS-CoV-2. This gives SARS-CoV-2 about a 100-1000 times greater chance than SARS-CoV when entering the body and affecting the lungs due to their ability to access greater depths within the body (Cyranoski 2020). Research to determine the pathogenicity of the strain led to proofs of the high stability of the COVID-19 viral genome (Wakida et al. 2020). While researchers hope for the virus to have a reduced infection rate due to the development of possible mutations over time, no such evidence of reduction was observed, probably because of the efficient genetic repair mechanism of the virus.

Further analysis of the structure of the virus and its comparisons and findings could be of great significance in our efforts to find an effective cure or better understand the virus itself. A systematic comparative study between SARS-CoV and SARS-CoV-2 led to the identification of 380 amino acid substitutions, which may have contributed to the functional and pathogenic divergence of the current strain ( $\mathrm{Pal}$ et al. 2020). While there were no substitutions in the amino acids of non-structural proteins, substitutions were observed in the amino acids of proteins nsp3 and nsp2, spike protein, RBD, underpinning subdomain, and $\mathrm{C}$-terminal of the receptorbinding subunit S1 domain. The SARS-CoV-2 genome was also proven to have much lower mutation rates and genetic diversity than SARS-CoV based on the current genome sequence data. These differences in mutation rates and genetic diversity between SARS-CoV-2 and SARS-CoV were also supported by studies that revealed higher genetic diversity and mutation rates of SARS for all the open reading frames (ORF) in the virus genome compared to SARS-CoV-2 (Jia et al. 2020).

\section{Comparative outline and treatment approaches}

SARS-CoV-2 spreads with greater ease from person to person, increasing the transmissibility and infection rate. Similarly, the deaths caused due to COVID-19 far outweigh SARS and MERS even though it has a lower case fatality rate. With the increasing infection and death rate following SARS$\mathrm{CoV}-2$, the need for a highly efficacious and immuneboosting vaccine remains vital. There are no specific, approved antiviral therapies for the treatment of SARS-CoV-2, in common with the previous SARS-CoV and MERS-CoV outbreaks (Avendano et al. 2003; Zumla et al. 2015). However, the World Health Organization (WHO) and national governments are taking possible measures for the drug and vaccine developments alongside considering the different treatment strategies, e.g., virus-targeted drugs, plasma and antibody therapies, and vaccines. Generally, symptomatic and supportive treatments are being provided to COVID-19 patients (General Office of National Health Commission 2020).

Furthermore, due to the high conservancy and high homology of four specific enzymes with the other two CoVs, the enzymes are considered as potential targets for drug development (Morse et al. 2020; Tsai et al. 2006; Anderson et al. 2009). The virus-targeted drug, remdesivir, showed broadspectrum activity against SARS-CoV-2 in vitro and showed antiviral and clinical effects on the other two, SARS-CoV and MERS-CoV, in cell and animal model-based studies (Sheahan et al. 2017; Warren et al. 2016; Brown et al. 2019; Sheahan et al. 2020; de Wit et al. 2020). Since this drug proved its effectiveness in only one case, it needs further validation and must undergo proper clinical trials to prove its effectiveness and safety for COVID-19 patients. Moreover, another drug known as chloroquine diphosphate has shown its effectiveness in showing visible virus clearance and slowing down the disease (Gao et al. 2020). However, the drug chloroquine used for malaria was seen to lead to sudden cardiac deaths. Furthermore, angiotensin-converting enzyme inhibitors act as inhibitory agents for ACE only and not ACE2; rather, they increase the concentration of ACE2, facilitating the entry and replication of SARS-CoV-2 (Fang et al. 2020). The existing variations of the viral antigens and the immune-suppression phenomena indicate that the development of SARS-CoV-2 vaccines is far more challenging.

\section{Conclusion}

Although SARS-CoV-2 exhibits several similarities to SARS$\mathrm{CoV}$ and MERS-CoV, several factors contribute to its unique characteristics. The increased affinity of SARS-CoV-2 to bind to ACE2 receptors and the existence of several other notable changes in its structure aid its faster transmission than other CoVs; several studies of $R_{0}$ values can again prove the increased transmissibility of this virus. However, $R$ 's value is rather imprecise and is affected by several factors, including the social dynamics of a population or public health measures. The scenario was observed when the $R_{0}$ value from January and that after the lockdown in Wuhan was compared, which had decreased from 3 to 1 . This represented that the $R_{0}$ estimates corresponding to SARS-CoV-2 and SARS-CoV were quite similar. Unlike SARS-CoV and MERS-CoV, SARS$\mathrm{CoV}-2$ infects both the upper respiratory tract and the lungs and is also known to spread without showing any visible signs or symptoms. SARS-CoV-2 also has more available and effective cleavage molecules compared to the other related coronaviruses. While drugs common to SARS-CoV and MERS-CoV seem to have been effective in some cases of 
SARS-CoV-2, a higher dose or a combination of these with other drugs may bring about adverse effects. These factors, along with the viral antigen variations and immunesuppression mechanisms, also make it challenging to develop a vaccine for SARS-CoV-2. Despite researchers working faster than ever towards developing vaccines or possible therapeutics as possible treatments for COVID-19, the concerns for their safety and validations remain. SARS-CoV-2 is an emerging pathogen and has already been found to have a significant number of differences in its structure, infection rate, and transmission. These factors influence the possibility that these differences and several other unknown characteristics of the virus contribute to its far deadlier nature compared to others - raising the question of a new dimension to virology.

\section{References}

Anderson J, Schiffer C, Lee S, Swanstrom R (2009) Viral protease inhibitors. Antiviral Strat:85-110. https://doi.org/10.1007/978-3-54079086-0 4

Astuti I, Ysrafil (2020) Severe acute respiratory syndrome coronavirus 2 (SARS-CoV-2): an overview of viral structure and host response. Diabetes Metab Syndr Clin Res Rev 14(4):407-412. https://doi.org/ 10.1016/j.dsx.2020.04.020

Avendano M, Derkach P, Swan S (2003) Clinical course and management of SARS in health care workers in Toronto: a case series. Cmaj 168(13):1649-1660

Benvenuto D, Giovanetti M, Ciccozzi A, Spoto S, Angeletti S, Ciccozzi M (2020) The 2019-new coronavirus epidemic: evidence for virus evolution. J Med Virol 92(4):455-459. https://doi.org/10.1002/jmv. 25688

Brown AJ, Won JJ, Graham RL, Dinnon KH III, Sims AC, Feng JY, Cihlar T, Denison MR, Baric RS, Sheahan TP (2019) Broad spectrum antiviral remdesivir inhibits human endemic and zoonotic deltacoronaviruses with a highly divergent RNA dependent RNA polymerase. Antivir Res 169:104541. https://doi.org/10.1016/j. antiviral.2019.104541

Chan J, Yuan S, Kok K, To, K, Chu H, Yang J, Xing F, Liu J, Yip C, Poon R, Tsoi H, Lo S, Chan K, Poon V, Chan W, Ip J, Cai J, Cheng V, Chen H, Hui C, Yuen K (2020a) A familial cluster of pneumonia associated with the 2019 novel coronavirus indicating person-toperson transmission: a study of a family cluster. Lancet 395(10223):514-523. https://doi.org/10.1016/S0140-6736(20) 30154-9

Chan J, Kok K, Zhu Z, Chu H, To, K, Yuan S, Yuen K (2020b) Genomic characterization of the 2019 novel human-pathogenic coronavirus isolated from a patient with atypical pneumonia after visiting Wuhan. Emerg Microbes Infect 9(1):221-236. https://doi.org/10. 1080/22221751.2020.1719902

Chu H, Chan J, Yuen T, Shuai H, Yuan S, Wang Y, Hu B, Yip C, Tsang J, Huang X, Chai Y, Yang D, Hou Y, Chik K, Zhang X, Fung A, Tsoi H, Cai J, Chan W, Ip J, Chu A, Zhou J, Lung D, Kok K, To K, Tsang O, Chan K, Yuen K (2020) Comparative tropism, replication kinetics, and cell damage profiling of SARS-CoV-2 and SARS-CoV with implications for clinical manifestations, transmissibility, and laboratory studies of COVID-19: an observational study. Lancet Microbe 1(1):e14-e23. https://doi.org/10.1016/j.jcmgh.2020.09. 017
Coutard B, Valle C, de Lamballerie X, Canard B, Seidah N, Decroly E (2020) The spike glycoprotein of the new coronavirus 2019-nCoV contains a furin-like cleavage site absent in $\mathrm{CoV}$ of the same clade. Antivir Res 176:104742. https://doi.org/10.1016/j.antiviral.2020. 104742

Cyranoski D (2020) Profile of a killer: the complex biology powering the coronavirus pandemic. Nature 581(7806):22-26. https://doi.org/10. 1038/d41586-020-01315-7

de Wit E, Feldmann F, Cronin J, Jordan R, Okumura A, Thomas T, Scott D, Cihlar T, Feldmann H (2020) Prophylactic and therapeutic remdesivir (GS-5734) treatment in the rhesus macaque model of MERS-CoV infection. Proc Natl Acad Sci 117(12):6771-6776. https://doi.org/10.1073/pnas.1922083117

Drosten C, Günther S, Preiser W, van der Werf S, Brodt H, Becker S, Rabenau H, Panning M, Kolesnikova L, Fouchier R, Berger A, Burguière A, Cinatl J, Eickmann $M$, Escriou N, Grywna K, Kramme S, Manuguerra J, Müller S, Rickerts V, Stürmer M, Vieth S, Klenk H, Osterhaus A, Schmitz H, Doerr H (2003) Identification of a novel coronavirus in patients with severe acute respiratory syndrome. N Engl J Med 348(20):1967-1976. https://doi.org/10.1056/ NEJMoa030747

European Centre for Disease Prevention and Control. 2020. $Q \& A O n$ COVID-19. Available at: https://www.ecdc.europa.eu/en/covid-19/ questions-answers. Accessed 31 July 2020

Fang L, Karakiulakis G, Roth M (2020) Are patients with hypertension and diabetes mellitus at increased risk for COVID-19 infection? Lancet Respir Med 8(4):e21. https://doi.org/10.1016/S22132600(20)30116-8

Fehr A, Perlman S (2015) Coronaviruses: An Overview of Their Replication and Pathogenesis. Coronaviruses, pp 1-23. https://doi. org/10.1007/978-1-4939-2438-7_1

Gao J, Tian Z, Yang X (2020) Breakthrough: chloroquine phosphate has shown apparent efficacy in treatment of COVID-19 associated pneumonia in clinical studies. BioSci Trends 14(1):72-73. https:// doi.org/10.5582/bst.2020.01047

General Office of National Health Commission (2020) Diagnostic and treatment protocol for novel coronavirus pneumonia (trial version 5). Available online at: http://www.gov.cn/zhengce/zhengceku/ 2020-02/05/content 5474791.html. Accessed 31 July 2020

Gisanddata.maps.arcgis.com (2020) Arcgis Dashboards. Available at: https://gisanddata.maps.arcgis.com/apps/opsdashboard/index. html\#/bda7594740fd40299423467b48e9ecf6. Accessed 31 July 2020

Guo G, Ye L, Pan K, Chen Y, Xing D, Yan K, Chen Z, Ding N, Li W, Huang H, Zhang L, Li X, Xue X (2020a) New insights of emerging SARS-CoV-2: epidemiology, etiology, clinical features, clinical treatment, and prevention. Front Cell Dev Biol 8. https://doi.org/ $10.3389 /$ fcell.2020.00410

Guo Y, Cao Q, Hong Z, Tan Y, Chen S, Jin H, Tan K, Wang D, Yan Y (2020b) The origin, transmission, and clinical therapies on coronavirus disease 2019 (COVID-19) outbreak - an update on the status. Military Med Res 7(1):11. https://doi.org/10.1186/s40779-02000240-0

Hoffmann M, Kleine-Weber H, Schroeder S, Krüger N, Herrler T, Erichsen S, Schiergens T, Herrler G, Wu N, Nitsche A, Müller M, Drosten C, Pöhlmann S (2020) SARS-CoV-2 cell entry depends on ACE2 and TMPRSS2 and is blocked by a clinically proven protease inhibitor. Cell 181(2):271-280.e8. https://doi.org/10.1016/j.cell. 2020.02.052

Jia, Y., Shen, G., Zhang, Y., Huang, K., Ho, H., Hor, W., Yang, C., Li, C. and Wang, W., 2020. Analysis of the mutation dynamics of SARSCoV-2 reveals the spread history and emergence of RBD mutant with lower ACE2 binding affinity. DOI: https://doi.org/10.1101/ 2020.04.09.034942 
Jiang S, Hillyer C, Du L (2020) Neutralizing antibodies against SARSCoV-2 and other human coronaviruses. Trends Immunol 41(5): 355-359. https://doi.org/10.1016/j.it.2020.03.007

King, A.M., Lefkowitz, E., Adams, M.J. and Carstens, E.B. eds., 2011. Virus taxonomy: ninth report of the International Committee on Taxonomy of Viruses (Vol. 9). Elsevier

Li X, Duan G, Zhang W, Shi J, Chen J, Chen S, Gao S, Ruan J (2020) A furin cleavage site was discovered in the $S$ protein of the 2019 novel coronavirus. Chin J Bioinform (In Chinese) 18(2):103-108. https:// doi.org/10.12113/202002001x

Lu R, Zhao X, Li J, Niu P, Yang B, Wu H, Wang W, Song H, Huang B, Zhu N, Bi Y, Ma X, Zhan F, Wang L, Hu T, Zhou H, Hu Z, Zhou W, Zhao L, Chen J, Meng Y, Wang J, Lin Y, Yuan J, Xie Z, Ma J, Liu W, Wang D, Xu W, Holmes E, Gao G, Wu G, Chen W, Shi W, Tan W (2020) Genomic characterisation and epidemiology of 2019 novel coronavirus: implications for virus origins and receptor binding. Lancet 395(10224):565-574. https://doi.org/10.1016/S01406736(20)30251-8

Morse J, Lalonde T, Xu S, Liu W (2020) Learning from the past: possible urgent prevention and treatment options for severe acute respiratory infections caused by 2019-nCoV. ChemBioChem 21(5):730-738. https://doi.org/10.1002/cbic.202000047

Mou H, Raj V, van Kuppeveld F, Rottier P, Haagmans B, Bosch B (2013) The receptor binding domain of the new Middle East respiratory syndrome coronavirus maps to a 231-residue region in the spike protein that efficiently elicits neutralizing antibodies. J Virol 87(16):9379-9383. https://doi.org/10.1128/JVI.01277-13

Pal M, Berhanu G, Desalegn C, Kandi V (2020) Severe acute respiratory syndrome coronavirus-2 (SARS-CoV-2): an update. Cureus. https:// doi.org/10.7759/cureus. 7423

Paraskevis D, Kostaki E, Magiorkinis G, Panayiotakopoulos G, Sourvinos G, Tsiodras S (2020) Full-genome evolutionary analysis of the novel coronavirus (2019-nCoV) rejects the hypothesis of emergence as a result of a recent recombination event. Infect Genet Evol 79:104212. https://doi.org/10.1016/j.meegid.2020. 104212

Payne, S., 2017. Family Coronaviridae. Viruses, pp149-158. DOI: https://doi.org/10.1016/B978-0-12-803109-4.00017-9

Petrosillo N, Viceconte G, Ergonul O, Ippolito G, Petersen E (2020) COVID-19, SARS and MERS: are they closely related? Clin Microbiol Infect 26(6):729-734. https://doi.org/10.1016/j.cmi. 2020.03.026

Phan T (2020) Genetic diversity and evolution of SARS-CoV-2. Infect Genet Evol 81:104260. https://doi.org/10.1016/j.meegid.2020. 104260

Robson F, Khan K, Le T, Paris C, Demirbag S, Barfuss P, Rocchi P, Ng W (2020) Coronavirus RNA proofreading: molecular basis and therapeutic targeting. Mol Cell 79(5):710-727. https://doi.org/10.1016/ j.molcel.2020.07.027

Schoeman D, Fielding B (2019) Coronavirus envelope protein: current knowledge. Virol J 16(1):69. https://doi.org/10.1186/s12985-019$1182-0$

Shang J, Wan Y, Luo C, Ye G, Geng Q, Auerbach A, Li F (2020) Cell entry mechanisms of SARS-CoV-2. Proc Natl Acad Sci 117(21): 11727-11734. https://doi.org/10.1073/pnas.2003138117

Sheahan TP, Sims AC, Graham RL, Menachery VD, Gralinski LE, Case JB, Leist SR, Pyrc K, Feng JY, Trantcheva I, Bannister R (2017) Broad-spectrum antiviral GS-5734 inhibits both epidemic and zoonotic coronaviruses. Sci Transl Med 9(396):eaal3653. https://doi. org/10.1126/scitranslmed.aal3653

Sheahan TP, Sims AC, Leist SR, Schäfer A, Won J, Brown AJ, Montgomery SA, Hogg A, Babusis D, Clarke MO, Spahn JE (2020) Comparative therapeutic efficacy of remdesivir and combination lopinavir, ritonavir, and interferon beta against MERS-CoV. Nat Commun 11:222. https://doi.org/10.1038/s41467-019-13940-6
Tai W, He L, Zhang X, Pu J, Voronin D, Jiang S, Zhou Y, Du L (2020) Characterization of the receptor-binding domain (RBD) of 2019 novel coronavirus: implication for development of RBD protein as a viral attachment inhibitor and vaccine. Cell Mol Immunol 17(6): 613-620. https://doi.org/10.1038/s41423-020-0400-4

Tang X, Wu C, Li X, Song Y, Yao X, Wu X, Duan Y, Zhang H, Wang Y, Qian Z, Cui J, Lu J (2020) On the origin and continuing evolution of SARS-CoV-2. Natl Sci Rev 7(6):1012-1023. https://doi.org/10. 1093/nsr/nwaa036

Tsai C, Lee P, Stollar V, Li M (2006) Antiviral therapy targeting viral polymerase. Curr Pharm Des 12(11):1339-1355. https://doi.org/10. 2174/138161206776361156

Wakida H, Kawata K, Yamaji Y, Hattori E, Tsuchiya T, Wada Y, Ozaki H, Akimitsu N (2020) Stability of RNA sequences derived from the coronavirus genome in human cells. Biochem Biophys Res Commun 527(4):993-999. https://doi.org/10.1016/j.bbrc.2020.05. 008

Walls A, Park Y, Tortorici M, Wall A, McGuire A, Veesler D (2020) Structure, function, and antigenicity of the SARS-CoV-2 spike glycoprotein. Cell 181(2):281-292.e6. https://doi.org/10.1016/j.cell. 2020.02 .058

Warren TK, Jordan R, Lo MK, Ray AS, Mackman RL, Soloveva V, Siegel D, Perron M, Bannister R, Hui HC, Larson N (2016) Therapeutic efficacy of the small molecule GS-5734 against Ebola virus in rhesus monkeys. Nature 531(7594):381-385. https://oi. org/10.1038/nature17180

Wölfel R, Corman V, Guggemos W, Seilmaier M, Zange S, Müller M, Niemeyer D, Jones T, Vollmar P, Rothe C, Hoelscher M, Bleicker T, Brünink S, Schneider J, Ehmann R, Zwirglmaier K, Drosten C, Wendtner C (2020) Virological assessment of hospitalized patients with COVID-2019. Nature 581(7809):465-469. https://doi.org/10. 1038/s41586-020-2196-x

World Health Organization (2020) Transmission of SARS-CoV-2: implications for infection prevention precautions: scientific brief, 09 July 2020 (No. WHO/2019-nCoV/Sci_Brief/Transmission_modes/ 2020.3)

Wrapp D, Wang N, Corbett K, Goldsmith J, Hsieh C, Abiona O, Graham B, McLellan J (2020) Cryo-EM structure of the 2019-nCoV spike in the prefusion conformation. Science 367(6483):1260-1263. https:// doi.org/10.1126/science.abb2507

Wu A, Peng Y, Huang B, Ding X, Wang X, Niu P, Meng J, Zhu Z, Zhang Z, Wang J, Sheng J, Quan L, Xia Z, Tan W, Cheng G, Jiang T (2020) Genome composition and divergence of the novel coronavirus (2019-nCoV) originating in China. Cell Host Microbe 27(3): 325-328. https://doi.org/10.1016/j.chom.2020.02.001

Yu F, Du L, Ojcius D, Pan C, Jiang S (2020) Measures for diagnosing and treating infections by a novel coronavirus responsible for a pneumonia outbreak originating in Wuhan, China. Microbes Infect 22(2): 74-79. https://doi.org/10.1016/j.micinf.2020.01.003

Zaki A, van Boheemen S, Bestebroer T, Osterhaus A, Fouchier R (2012) Isolation of a novel coronavirus from a man with pneumonia in Saudi Arabia. N Engl J Med 367(19):1814-1820. https://doi.org/ 10.1056/NEJMoa1211721

Zhou P, Yang X, Wang X, Hu B, Zhang L, Zhang W, Si H, Zhu Y, Li B, Huang C, Chen H, Chen J, Luo Y, Guo H, Jiang R, Liu M, Chen Y, Shen X, Wang X, Zheng X, Zhao K, Chen Q, Deng F, Liu L, Yan B, Zhan F, Wang Y, Xiao G, Shi Z (2020) A pneumonia outbreak associated with a new coronavirus of probable bat origin. Nature 579(7798):270-273. https://doi.org/10.1038/s41586-020-2012-7

Zhu N, Zhang D, Wang W, Li X, Yang B, Song J, Zhao X, Huang B, Shi W, Lu R, Niu P, Zhan F, Ma X, Wang D, Xu W, Wu G, Gao G, Tan W (2020) A novel coronavirus from patients with pneumonia in China, 2019. N Engl J Med 382(8):727-733. https://doi.org/10. 1056/NEJMoa2001017 